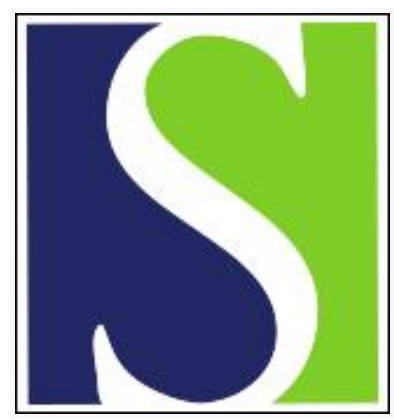

Scand J Work Environ Health 2010;36(2):96-108

https://doi.org/10.5271/sjweh.2894

Published online: 20 Jan 2010, Issue date: 00 Mar 2010

Shift work and cardiovascular disease - pathways from circadian stress to morbidity

by Puttonen S, Härmä M, Hublin C

Affiliation: Centre of Expertise on Human Factors at Work, Finnish Institute of Occupational Health, Fl-00250 Helsinki, Finland. sampsa.puttonen@ttl.fi

Refers to the following texts of the Journal: 2006;32(6):502-514 1999;25(2):85-99 1989;15(3):165-179 2009;35(3):163-179 2009;35(3):157-161 2006;32(6):413-419 2006;32(6):431-442 2001;27(2):97-105 1999;25(4):376-381 1997;23(4):257-265 2009;35(1):48-55 1998;24 suppl 3:141-145 SJWEH Supplements 2008;(5):14-21 2004;30(2):139-148 2004;30(2):149-156

The following articles refer to this text: $2010 ; 36(2): 81-84$; 2011;37(1):62-69; 2011;37(1):54-61; 2011;37(4):263-275; 2012;38(1):1-3; 2012;38(4):343-348; 2014;40(3):287-294; 2014;40(6):557-568; 2014;40(6):621-630; 2015;41(1):54-64; 2015;41(1):84-93; 2015;41(3):259-267; 2015;41(3):268-279; 2016;42(6):459-468; 2016;42(6):455-457; 2017;43(2):117-126; 2017;43(2):127-135; 2017;43(3):250-259; 2017;43(6):569-577; 2018;44(3):229-238; 2018;44(3):251-257; 2018;44(3):265-273; 2018;44(4):403-413; 2019;45(5):465-474; 2020;46(5):516-524; 2021;47(3):200-207; 2021;47(8):565-581; 2022;48(1):31-40; 2022;48(7):511-519; 2022;48(7):520-529

Key terms: cardiovascular disease; circadian stress; coronary heart disease; CVD; health; health; literature review; morbidity; review; shift work; stress; workhours; working hours

This article in PubMed: www.ncbi.nlm.nih.gov/pubmed/20087536

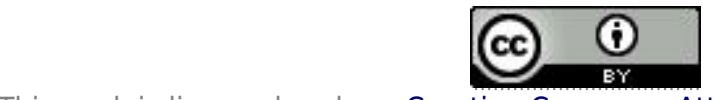




\title{
Shift work and cardiovascular disease - pathways from circadian stress to morbidity
}

\author{
by Sampsa Puttonen, PhD, ${ }^{1}$ Mikko Härmä, MD, PhD, ${ }^{1}$ Christer Hublin, MD, PhD ${ }^{1}$
}

\begin{abstract}
Puttonen S, Härmä M, Hublin C. Shift work and cardiovascular disease - pathways from circadian stress to morbidity. Scand J Work Environ Health. 2010;36(2):96-108.

In order to establish a causal relation between shift work and cardiovascular disease (CVD), we need to verify the pathways from the former to the latter. This paper aims to review the current knowledge of the mechanisms between shift work and CVD. Shift work can increase the risk of CVD by several interrelated psychosocial, behavioral, and physiological mechanisms. The psychosocial mechanisms relate to difficulties in controlling working hours, decreased work-life balance, and poor recovery following work. The most probable behavioral changes are weight gain and smoking. The plausible physiological and biological mechanisms are related to the activation of the autonomic nervous system, inflammation, changed lipid and glucose metabolism, and related changes in the risk for atherosclerosis, metabolic syndrome, and type II diabetes. The data provide evidence for possible disease mechanisms between shift work and CVD, but compelling evidence on any specific mechanism is missing.
\end{abstract}

Key terms CHD; coronary heart disease; CHD; CVD; literature review; working hour.

Despite two decades of reviews, there is still no consistent evidence that shift work increases the risk of cardiovascular disease (CVD) (1-3). Most epidemiologic research on the area has focused on the risk for coronary heart disease (CHD). In the latest review based on 16 studies, Frost and coworkers (3) concluded there was limited evidence for a causal relationship between shift work and ischemic heart disease. The term "limited evidence" (3) refers to the fact that a casual relationship between the exposure and disease is possible but could be explained by chance, bias, or confounding.

The review by Frost et al (3) showed a stronger association between shift work and morbidity than mortality, suggesting that selection out of shift work or, for example, the use of occupational health screening could weaken the association with mortality. Moreover, CVD is most common among the elderly who are no longer exposed to work-related risk factors of CVD. In a 13-year follow-up study of the Helsinki Heart Study, the relative risk of CHD among shift workers was 1.59 after 5 years. After 13 years, when most of the workers were retired, the risk had decreased to 1.34 (4). The somewhat inconsistent epidemiologic evidence on the association between shift work and CVD is mostly due to common problems in exposure assessment and the selection of a proper control group. Inconsistencies also arise from primary, secondary, and tertiary selection and some may be the result of controlling statistically for the pathways in addition to confounders (5).

In order to interpret the epidemiological data correctly, it is necessary to understand the pathways and possible mechanisms mediating the effects of shift work on CVD. We are not aware of any recent reviews on the mechanisms linking shift work to CVD. Ten years ago, Bøggild \& Knutsson (1) concluded that there are different but interrelated pathways that may lead from shift work to disease in general, namely: mismatch of circadian rhythms, social disruption, behavioral changes, and changes in the biomarkers of atherosclerosis. During more recent years, the literature on all four of these pathways has grown considerably. In addition to new studies on biomarkers of atherosclerosis, direct evidence on the association between shift work and atherosclerosis is also emerging $(6,7)$.

This narrative review aimed to discuss the current knowledge on the different pathways from shift work to CVD, which include three major categories: CHD, cerebrovascular disease, and peripheral vascular disease.

\footnotetext{
${ }^{1}$ Finnish Institute of Occupational Health, Helsinki, Finland.
}

Correspondence to: Sampsa Puttonen, Centre of Expertise on Human Factors at Work, Finnish Institute of Occupational Health, Topeliuksenkatu 41a A, FI-00250 Helsinki, Finland. [E-mail: sampsa.puttonen@ttl.fi] 
Our focus was on the pathways related to the atherosclerotic manifestations of the CVD. The review was based on a model where the circadian stress due to working in shifts can induce three different major pathways from shift work to the CVD: a behavioral, psychosocial, and physiological one (figure 1).

Shift work is defined as either work at changing hours of the day (eg, morning, afternoon, and night shift) or work at constant but unusual hours of the day (eg, permanent afternoon shift or permanent night shift) (8). CVD are a group of disorders of the heart and blood vessels (9). The term circadian stress refers to the physiological, behavioral, and psychosocial consequences related to the disturbances of the human circadian rhythm (eg the sleep-wakefulness rhythm). The timing of 24-hour operations is the major challenge in organizing shift work as well as being one of the major causes of circadian stress. However, shift work may or may not include night work and, besides night work, other unusual or irregular working hours may also cause circadian stress (eg, early morning work). Work stress refers to those aspects of work design, organization, and management, and their social and organizational contexts, that have the potential to cause harm to employee health (10).

\section{Psychosocial stress as a pathway}

There is evidence that both socioeconomic status and work stress are risk factors for CVD $(11,12)$. A systematic review and meta-analysis by Kivimäki et al (12) concluded that work stress, defined by three prevalent work stress models, was associated with a $50 \%$ excess risk of CHD according to prospective studies. Although the individual studies on job strain are partly inconsistent, an association between low job control and the risk of ischemic heart disease has been repeatedly found $(13,14)$. Since shift work is associated with both socioeconomic status and psychosocial factors at work (15), the independency of shift work as a risk factor for CVD has been questioned. Despite having controlled for differences in work demands and work stress, some prospective studies have found a significant association between shift work and CVD (16-18). Shift work can act as a specific "circadian" psychosocial stress factor in several ways. First, shift work may increase psychosocial stress due to inflexibly organized shifts that leave limited possibilities for employees to influence their working hours. Second, shift work is described as comprising "unsocial" working hours since it may decrease the work-life balance due to possible variability and/or unsocial timing of leisure time. Finally, shift work may increase the perception of insufficient recovery from work.

\section{Shift work and work stress}

In relation to the job strain model (19), shift work has been associated with lower job control compared to day work, while work demands and social support do not seem to differ $(15,20,21)$. Based on a random sample of Danish employees, conflicts at work and low decision latitude were higher among all groups of shift compared to day workers (15). Differences in work stress between shift and day workers vary between occupations, but there may also be differences within occupations. In eldercare, for example, women in fixed non-day

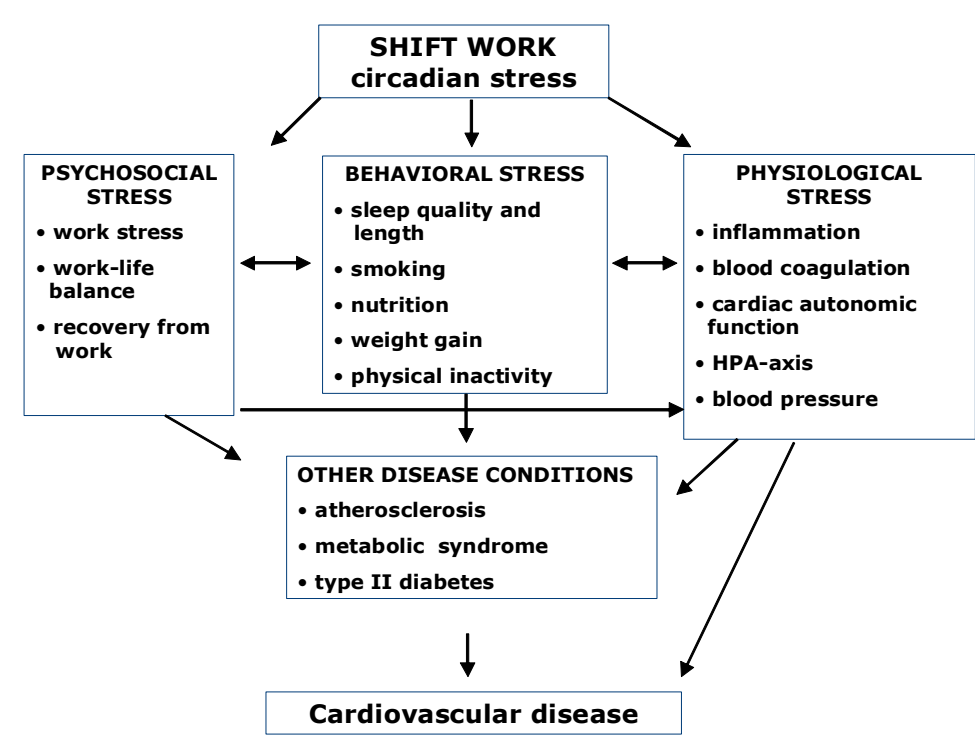

Figure 1. Model for pathways from shift work to cardiovascular disease. 
shifts were more often exposed to low job control and decreased support from supervisors and had a higher risk of physical and psychological violence (22). Karasek's job control factor does not include work-time control or control over work scheduling. However, perceived control over working hours, which has been shown to predict decreased sickness absence and a good subjective health (23), correlates highly with job control (24).

Another commonly used work stress model, the effort-reward imbalance model of Siegrist et al (25) focuses on a person's perception of the balance between his or her efforts at work and the rewards received. The different aspects of working hours are not directly covered by the model, but both indicators of effort-reward imbalance (ie, a need for control and approval and unfavorable effort-reward ratio) are more prevalent among shift than day workers (17). However, in addition to the suggested mediating effects of effort-reward imbalance at work for CVD risk factors, including hypertension and atherogenic lipids, shift work has also direct effects on these risk factors (17).

\section{Shift work, work-life balance, and recovery}

Shift work and irregular working hours can disturb the work-life balance. Even after adjustment for work stress, working in shifts decreases the perceived balance between work and social life (26-29). For example, compared to day work, baseline shift work was associated with higher work-home interference over time in the Maastricht cohort study (28).

A good work-life balance means an appropriate mixture of work and recovery. A high need for recovery predicted an increased incidence of self-reported CVD in a 2.5-year follow-up among healthy employees at baseline (30). Similarly, employees who seldom recovered from work during free weekends had an elevated risk of death due to heart disease even after controlling for age, gender, and 16 risk factors, including fatigue, lack of energy, and job stress (31). Shift work is related to a greater need for recovery $(32,33)$. Working hours define the time left for social activity and sleep that may be used for recovery either during the work (work breaks) or afterwards (leisure time). Based on this, the effort-recovery stress model (34) suggests that the negative consequences of work hours on health depend on the possibilities for recovery during and after work.

In conclusion, shift work may induce psychosocial stress through (i) greater difficulties to control personal working hours, (ii) decreased work-life balance, and (iii) insufficient recovery. Although the basic differences in work stress between day and shift workers may at least partly mediate the association between shift work and the risk of heart disease, shift work also includes specific psychosocial stress factors relevant for CVD.

\section{Behavioral stress as a pathway}

Shift work is associated with circadian disruption that also affects behavior. One of the most notable changes can be observed in sleep-wake patterns; from time to time, the main sleep period is temporally displaced and the worker suffers from sleep debt, insomnia, and/or excessive sleepiness. This is most notable in night shifts but also seen in early-morning and late-evening shifts. Other aspects of behavior which may change are smoking, consumption of alcohol, dietary intake, and physical exercise.

\section{Sleep quality and length}

Epidemiologic studies since the 1960s have shown that sleep duration is associated with a risk of mortality. The association is U-shaped, with the lowest risk in those sleeping 7 hours (about the average length in the general population). In a recent meta-analysis (35), the pooled relative risk (based on 16 studies with sufficient data) for all-cause mortality for short sleep duration ( $<7$ hours) was significantly increased $(10 \%$ higher compared to those sleeping 7-8 hours). However, cardiovascularrelated mortality was non-significantly increased (6\%).

Sleepiness is over-represented in shift/night workers. In many studies, a majority of shift workers admit to having experienced involuntary sleep on the night shift, whereas this is rare in day-oriented shifts (36). Insufficient sleep and sleepiness activate the sympathetic nervous system and lead to increases in blood pressure and heart rate (37). A study among young, healthy individuals found that only 6 consecutive nights of bedtime restricted to 4 hours per night increased the activity of the sympathetic nervous system and evening cortisol concentrations and decreased glucose tolerance (38). On the other hand, sleep deprivation increases hunger and decreases leptin, a factor inhibiting hunger (39). Experimental short-term sleep deprivation also increases the peripheral circulation of leukocytes, interleukins, and C-reactive protein, the last of which is a predictor of the risk of stroke and myocardial infarction (40-42).

Shortened or disturbed sleep is among the most common health-related effects of shift work $(43,44)$. The effects on sleep length depend on whether the shifts are permanent or rotating, in the latter case the speed and direction of rotation have an impact. In a meta-analytic review, based on 36 primary studies, Pilcher et al (45) concluded that permanent night shifts result in a decrease in the length of sleep (mean 6.6 hours), whereas permanent evening shifts result in an increase (mean 7.6 hours). Furthermore, the shifts within rotating schedules followed the same pattern (mean night 5.9 and evening 8.0 hours), with the addition of morning shifts having a moderate detrimental effect on sleep length (mean 6.6 hours). 
The International Classification of Sleep Disorders (46) includes criteria for "shift work sleep disorder". In one of the few epidemiological studies on this subject, $8 \%$ of shift workers and $14 \%$ of nighttime workers were found to suffer from the disorder (47). Still, shift work does not appear to be a major source of insomnia and the level of sleep complaints bear no resemblance to those seen in insomniac patients (36). This shift work sleep disorder study showed very few differences between shift and day workers; only "too little sleep" and "nodding off at work" were higher among shift compared to day workers.

\section{Smoking}

The association between smoking and shift work has been the subject of much debate. Many studies have shown that smoking is more prevalent among shift than daytime workers, but most studies have been crosssectional or queried about smoking only once. Bøggild \& Knutsson (1) concluded that, in seven "positive" studies (out of 13), the excess prevalence of smoking was $10-40 \%$. The systematic review of Frost et al (3) was based on 14 studies, of which six reported on smoking and found that it was generally more frequent among shift workers. In recent studies with information on smoking, results have been mixed, indicating either no increase (48), a slight increase [3.9\% (49) and about $10 \%$ (50)], or a significant increase (7) of smoking among shift workers.

It has also been suggested that smoking should be regarded as a mediator of CVD, as it may be a way of staying awake during the night shift and, therefore, could be regarded as a causal chain variable (51). Preemployment smoking has been controlled for only in two case-control studies (3). A two-year follow-up study showed a significantly increased risk (46\%) of starting smoking among shift compared to day workers (52). In a one year follow-up study, shift work was quite strongly associated both with smoking status and starting to smoke at a later date; it was concluded that smoking status should not solely be treated as a mediator but also considered a confounder (53).

\section{Nutrition}

There have been some studies on dietary changes in association with shift work. In a Swedish study, Lennernäs et al (54) found that working two and three shifts affected the circadian distribution of food and coffee consumption but not the overall 24-hour consumption. In a Japanese study (55), there were no significant differences in nutrient intake between fixed daytime and non-night shift workers. On the other hand, energy intake was highest during the night shift particularly among middle-aged workers.
Studies assessing lipids in shift workers have had variable results. Of 16 studies, 5 showed increased cholesterol levels; 3 of these were prospective studies (1). In a follow-up study by Morikawa et al (56), the increases in total cholesterol were similar among day and shift workers. On the contrary, a methodologically similar 14-year follow-up study found a higher increase in total cholesterol among Japanese shift workers (57). In an Italian male cohort with repeated health examinations, night workers had significantly higher total cholesterol than their daytime colleagues (58). Regarding triglycerides, higher values were found among shift workers in 4 of 12 studies (1). Similarly, more recent studies have shown variable results [no difference (59) or elevated (60)].

\section{Weight gain}

Shift work may also influence weight gain through reduced sleep. A meta-analysis of 26 cross-sectional studies indicated an increased obesity among those with shorter sleep times (mostly $\leq 5$ hours (61). However, in their critical review (62), Marshall and colleagues concluded that it was unclear from the available adult epidemiological literature if short sleep and obesity or weight gain are associated. Some studies have indicated that starting shift work may be related to gains in body weight (3). Suwazono et al (63) reported a significantly increased risk (1.14) of $\geq 5 \%$ weight gain among shift compared to daytime workers. Similarly, Morikawa et al (56) found a significant increase in body mass index (around $1 \mathrm{~kg} / \mathrm{m}^{2}$ ) among those working continuously in shifts and those changing from daytime to shift work. In the aforementioned Italian male cohort with repeated health examinations, night workers had significantly higher body mass index than daytime workers (58).

\section{Other behavioral aspects}

There are no consistent results on differences in alcohol consumption or exercise between shift workers and the general population (1). Recent studies have shown no significant difference in either case among men $(7,49)$; among women, a significant decrease in physical activity and a non-significant decrease in alcohol consumption have been reported (7).

\section{Physiological stress and reactions as a pathway}

In order to establish a causal relation between shift work and CVD, we need to point out the specific underlying physiological and biological mechanisms that influence the disease process at different phases. We have summed up the results of studies using established independent 
biochemical or physiological risk factors of CVD but also incorporated studies using other suggested markers. By doing this, we have provided a more comprehensive picture of the evidence and can point to the need for further research. The examined mechanisms and risk factors of CVD range from inflammation, blood coagulation, physiological and biological stress mediators (autonomic nervous system and hypothalamic-pituitaryadrenal axis, which control the body's levels of cortisol and catecholamine), and blood pressure to disease conditions such as hypertension and type II diabetes.

\section{Inflammation}

Inflammation plays a critical role in the atherosclerotic process, all stages of atheroma formation, and CHD (64). Several markers of inflammation have been associated with CVD risk. However, only a small number of studies have tested whether the mechanism is active in the observed shift work-CVD association. High sensitive C-reactive protein, leucosyte count, lymphosyte, and NK-cell activity have received some interest in shift work studies. Sookoian et al (60) and Nishitani et al (65) reported an increased leucocyte count among rotating shift compared to daytime workers. In addition, 3-shift work has been associated with reduced T-lymphosyte function $(66,67)$. In more recent studies, NK-cell activity was lower among shift compared to daytime workers; among shift workers, activity was also lower during night as compared to day shifts $(68,69)$.

\section{Homocysteiene and blood coagulation}

Plasma homocysteine is an independent risk factor for atherosclerosis and CVD (70) and potentially influences several risk mechanisms of CVD, including endothelial dysfunction, oxidative stress, and atherogenic inflammation (71). At least three cross-sectional studies have examined the association between homocysteine and shift work. Homocysteine levels have been reported to be increased in shift work, but no difference has been found in the prevalence of hyperhomocysteinemia [defined as levels exceeding the normal value $(>15 \mathrm{mmol} / \mathrm{l})](72,73)$. The level of homocysteine was found to be almost twice as high among male shift compared to day workers (73), while another study reported significantly increased levels only for older shift working men with sleep complaints (74). The current evidence suggests that there may be some association between shift work and homocysteine, but the evidence is thin and far from conclusive. The same holds true for microalbuminuria, which is a risk marker for arterial thromboembolism (75) and a predictor of CVD mortality and cardiac events (76). The association between shift work and albumin excretion has been examined in one study, suggesting that shift workers may have increased excretion compared to day workers (77). Similar levels of fibrinogen among day and shift workers have been reported (78), while another study on plasminogen activator and tissue plasminogen activator inhibitor showed lower fluctuations among those working shifts both during the day and night, suggesting some deficiency in the diurnal variation of blood coagulability (79).

\section{Cardiac autonomic function}

Shift work may influence acutely autonomic function, increasing cardiac sympathetic and decreasing parasympathetic activity during work and sleep following a work period. Over 15 studies using field measures have reported lower levels of parasympathetic modulation of heart rate variability or increased sympathetic activity in shift work (for example 68,80-84). Others have reported that nighttime work is associated with reduced cardiac sympathetic modulation (81). Shift work may predispose individuals also to prolongation of QT intervals corrected for heart rate (QTc) (85), indicating a possible pro-arrhythmic potential of shift work. Indeed, a follow-up study of employees starting their work indicated that shift workers had increased frequency of ventricular extrasystoles, which correlated with the number of nights worked (86).

\section{Cortisol and catecholamine}

There is relatively little evidence supporting the hypothesis that cortisol would be directly associated with the development of CVD. However, cortisol and catecholamines may influence stress-induced heart disease (87). Studies have demonstrated that shift work may acutely alter the regulation of cortisol $(83,88-91)$. Typically, studies have explored how cortisol secretion alters during shift work and cortisol measures have been used as an indicator of adaptation to shift work, rather than as a possible health risk factor as such. We could not find any studies on the possible enduring effects of shift work on cortisol secretion. Disturbed cortisol secretion and/or altered timing may influence health risk factors such as the development of central obesity.

Little is known about the relation between shift work and catecholamines. The simulated shift work study of Boucsein et al (92) found that adrenalin and noradrenalin excretion rates were significantly higher under day compared to night shifts, and lower during sleep compared to work. In the study of Theorell et al (93), clear fluctuations in the diurnal pattern of catecholamine excretion during and after night work were observed. Catecholamine secretion shows a distinct circadian variation and the timing of sample collection is critical in shift work studies. Therefore, it is possible that the 
observed changes in catecholamine levels may reflect the circadian phase differences, which makes it difficult to interpret the findings in many cases.

\section{Atherosclerosis and other preceding disease conditions}

Atherosclerosis. Up to now, two studies have explored the association of shift work with the atherosclerotic process. These studies have used ultrasonic measures to estimate the level of subclinical atherosclerosis of the carotid intima media. Haupt and colleagues (6) reported an increased risk among shift workers in a sample of participants $\geq 45$ years. A similar positive association for males was found in a study focusing on younger day and shift workers (24-39 years old) (7).

Endothelial dysfunction is an early finding and marker in the development of atherosclerosis. Brachial artery endothelial function was acutely reduced after a 24-hour shift (94). The greatest decrease in flow-mediated dilation was observed among participants with a longer history of night shift duty.

Type // diabetes. At least six studies have looked at the association between shift work and diabetes (95-100). Five of them have been cohort studies of type II diabetes incidence with follow-up periods ranging from 4-10 years; one study is on the mortality risk due to diabetes. Two reports of the nurses' health study $(95,96)$, with partially overlapping data, concluded that shift work predicts a higher incidence of type II diabetes, with an increasing risk as a function of exposure to irregular working hours; the study also found that obesity may mediate the effect of shift work on diabetes risk. A Swedish study with male participants found a positive association between the number of years worked in shifts and mortality due to diabetes (97), while Kawakami et al (98) did not find any significant excess risk of incidence of diabetes in shift work. Two studies that used glycated hemoglobin and/or medication as the indicator of diabetes status, reported both a non-significant trend towards an increased risk (99) and an increased multivariate risk of diabetes in shift work (100).

Metabolic syndrome (MetS). MetS, a risk factor of CVD, is a clustering of cardiac health risk factors such as insulin resistance, hypertension, cholesterol abnormalities, and central obesity (101). Existing cross-sectional studies have either looked at the association between shift work and components of the MetS (58, 59, 102, 103 ) or the prevalence of MetS according to a standard formulation of the syndrome $(60,104)$. A general conclusion of the studies is that shift work has relatively consistent associations with individual risk factors of MetS and perhaps a more consistent association when the syndrome is considered as a whole. In addition, recent prospective cohort studies that used international formulations of the MetS have added to this evidence by showing that shift work increases the risk of incidence of MetS. In these studies, the relative risk in shift work has varied from $1.5-5.0(105,106,107)$ suggesting a causal relationship between night shift work and the development of MetS. International formulations - such as those of the National Cholesterol Education Program's Adult Treatment Panel III (NCEP-ATP III), the International Diabetes Federation (IDF), and the European Group for the study of Insulin Resistance (EGIR) - use different criteria for defining MetS. This may also have some impact on the findings. For example, Esquirol et al (104) used both the NCEP-ATPIII and IDF criteria and reported that shift work was associated with NCEPATPIII MetS but not with IDF MetS, a formulation which emphasizes more abdominal obesity. The comparability between studies would be facilitated if standard and multiple definitions of MetS were used.

Blood pressure and hypertension. Studies have examined the role of shift work in resting blood pressure levels and daily blood pressure in field circumstances, and whether shift work may influence the circadian profile of blood pressure. Cross-sectional epidemiological studies do not suggest a significant association between shift work and blood pressure. Studies have reported similar levels of blood pressure in shift and day workers $(58,59,85$, $104,108)$, while in some studies the former have had significantly higher blood pressure levels than day workers $(60,109)$. When changes in blood pressure levels are considered, a fairly similar picture emerges: some longitudinal studies have suggested that rotating shift work is a risk factor for an increase in blood pressure $(110,111)$, while others have found no effect of shift work on blood pressure increment $(56,112,113)$.

Hypertension has been found to be more prevalent among shift compared to day workers (114) or among shift workers only in a certain age group (40-49 years old) (103). In the study by Morikawa et al (115), a higher risk of incident hypertension among shift workers was evident only in younger participants, while among the older participants a high risk of hypertension was found for those who changed from shift to day work during the follow-up. Furthermore, longer exposure to shift work has been reported to predict the onset of hypertension among males $>30$ years old (102); in the same study, shift work was suggested to be associated inversely with hypertension among young women $<30$ years of age. Finally, shift work has been shown to predict the onset of hypertension among male workers (116) as well as the progression from mild-to-severe hypertension (117).

Shift work may exert transient and long-term effects on circadian blood pressure control seen as the change from a "dipping" to "non-dipping" pattern in which the 
normally observed nocturnal decrease in blood pressure during sleep is impaired. In a study by Yamasaki et al (118), shift workers had a smaller drop in the systolic blood pressure during sleep than day workers, and they were more often categorized as "non-dippers". Shift work has also been associated with higher 24-hour blood pressure levels $(119,120)$, while the risk of non-dipper status yielded mixed results. The mean systolic blood pressure during a 24-hour measurement has been found to be higher among shift than day workers (110). In a 24-hour monitoring study (121), blood pressure was higher during daytime sleep than sleep that occurred at night, a finding that may point to non-dipping phenomena but may also reflect the circadian variation of blood pressure. Kitamura et al (122) reported a transient effect of shift work on dipping at the beginning of night shift work. This was reversed to a dipping pattern after four days of work.

The reviewed data showed mixed results for blood pressure levels and longitudinal increases in blood pressure in shift work. There appears to be limited evidence suggesting that shift work may acutely increase 24-hour blood pressure and have transient and long-term effects on dipper-status. In addition, whether shift work can increase the risk of hypertension needs to clarifed in additional follow-up studies. If shift workers, however, develop higher systolic blood pressure levels than day workers, it entails a high CHD risk (113). In the future, the role of treatment of hypertension should also be better taken into account. We do not know, for example, about the possible effects of blood pressure medication in many of the previous studies. Moreover, it is recommended to treat the use of such medication as an outcome measure in shift work studies, as is currently being done in studies of MetS risk.

\section{Discussion}

During the last two decades, a high number of epidemiologic studies have investigated the evidence on the relationship between shift work and CVD. Although epidemiologic data have grown, the lack of evidencebased mechanisms from shift work to CVD has made the interpretation and analysis of such data difficult. The present evidence points to several possible pathways from shift work to CVD. Although evidence on the strength of any individual mechanism is still limited, the number of studies on different pathways has been increasing relatively fast during the last ten years. Also, studies on essential mechanisms such as atherosclerotic process have gained support $(6,7)$. Several of the biomarkers related to shift work are also related to the atherosclerotic process: inflammation, increased blood cholesterol, homocystein, and albumin levels, in addition to the possible deficiencies in endothelial function and blood coagulation.

The mechanisms by which shift work could be a risk factor for CVD range from the effect of varying working hours to the circadian body functions, but shift work also interferes with the social and domestic life. Besides changing the rhythm of work, shift work changes simultaneously the behavioral rhythms in sleep, activity, and nutrition. We therefore conclude that there is sufficient evidence for possible disease mechanisms from shift work to CVD, but strong evidence on any specific plausible mechanism is missing. Shift work could increase the risk of CVD by several psychosocial, behavioral, and physiological mechanisms. The different pathways are interrelated and may also lead to other metabolic diseases by increasing the risk for atherosclerosis, metabolic syndrome, and type II diabetes.

There are several reasons for preferring a narrative as opposed to systematic review. First, the area covered by our review is large and the relevant mechanisms include dozens of variables to be evaluated. Second, many of the variables have been little studied and methodologically good studies are quite scarce (eg, long follow-up studies with large populations and adequate control of confounders). Third, probably largely because of variable methodology, the results of different studies are often contradictory. Consequently, we have chosen the narrative form and tried to emphasize the results of methodologically strong studies.

\section{Psychosocial stress}

We conclude that there is evidence that shift work can induce psychosocial circadian stress due to a lack of control over working hours, problems in the work-life balance, and decreases in perceived recovery. It is obvious that shift systems vary according to their psychosocial effects, with some shift systems suiting even better to personal time constraints than others. Job control is a key element of work stress in several stress concepts. Since both job control and the perception of sufficient recovery after work are independently related with CVD $(12-14,31)$, it is quite possible that shift work could increase the risk for CVD through its psychosocial stress mechanism.

Poor job control, work-life imbalance, and insufficient recovery can further induce behavioral and physiological stress reactions. Due to psychosocial stress factors, shift workers may sleep less, start smoking, and develop unhealthy eating habits. Psychosocial and behavioral stress could trigger the physiological stress reactions linking the psychosocial stress to the pathophysiological mechanisms of CVD. 


\section{Behavioral stress}

Both short sleep and insomnia have been reported to increase the risk for CVD $(123,124)$. Although sleeping $<7$ hours is related to the risk of total mortality, this does not seem to be mediated through CVD (35). It is possible that the mean sleep length of shift workers is not significantly reduced over a longer period. The sleep problems among shift workers also seem to be milder than among insomniacs $(36,125)$. Generally, sleep quality is not an independent risk factor of a health outcome (risk of mortality) if sleep length is taken into account (126). So far, there is limited evidence to support the view that reduced quantity or quality of sleep (per se) would be a major pathway to affect the risk of CVD in shift work, but they might contribute to adverse physiologic changes via intermittent excessive sleepiness.

There is evidence to suggest that smoking is more prevalent among shift than daytime workers, and if this is confirmed in future studies this could be one possible pathway affecting CVD risk. The situation is similar regarding serum lipids. There is more evidence on the risk of weight gain among shift workers, and at present this seems to be the most verified of the possible behavioral pathways from shift work to CVD.

\section{Physiological stress reactions}

CVD develops over a long period with physical changes beginning decades before the disease manifests itself; some of the health hazards of shift work may remain undetected when a disease condition is used as an endpoint, as employees may, for example, change to day work when the first symptoms of CVD occur. Therefore it is important to focus on the mechanisms of the subclinical phase.

When summing up the evidence on the findings of biological and physiological risk factors in the shift work-CVD association, several conclusions arise. Looking at studies using the reviewed individual biological or physiological risk factors of CVD, it is clear that none of these possible mechanisms receive strong support at the moment. This is partially due to the fact that biological markers of immune function, blood coagulation, and oxidative stress have been rarely studied. One reason for the low number of epidemiologic studies is that the data have been obtained from regular physical health check-ups with standard sets of measures. There are, however, studies (usually with smaller numbers of participants) providing important additional knowledge on new biological and physiological risk factors. Regarding individual factors, there is some evidence suggesting that inflammation may serve as a pathophysiological pathway. Also homocysteine has received some evidence. The main stress mediators, hypothalamic- pituitary-adrenal axis and autonomic nervous system, have been widely studied with regard to shift work. These studies have concluded that shift work has acute effects on the stress mediators' levels and diurnal variation, thus potentially increasing harmful allostatic load. However, this evidence is only indirect, and we could not find any studies on longitudinal effects. In future, it would be important to study the effects of shift work on, for example, cortisol and heart rate variability in population cohorts.

Several cross-sectional and longitudinal studies have tested whether blood pressure and hypertension would serve as a mediating risk factor. The findings of crosssectional studies have yielded mixed results, which is not very surprising considering the known problems in shift work research. Follow-up studies suggest that there may be some increment of risk related to shift work, but whether this is a true effect remains to be clarified in future studies. Subclinical atherosclerosis has been studied in two large cohorts. These studies showing an increased risk in shift workers did not have follow-up on atherosclerosis and thus longitudinal studies are needed to confirm the association. Recently a relatively high number of shift work studies have focused on MetS and type II diabetes, and the current data suggests that shift work is a probable risk factor for both. Although a number of longitudinal studies have been published, it still is premature to make firm conclusions and future studies should use established definitions of conditions to ensure better comparability between studies.

\section{Concluding remarks and need for further research}

This narrative review has examined the psychosocial, behavioral, and physiological mechanisms by which shift work could be a risk factor for CVD and concludes that there is sufficient evidence for possible disease pathways - although strong evidence on any specific plausible mechanism is so far missing. These pathways are interrelated and may lead to other cardiovascular and metabolic diseases by increasing the risk for atherosclerosis, metabolic syndrome, and type II diabetes.

In general, there are numerous methodological challenges in studying the possible mechanisms of the shift work-CVD relationship. First, there are aspects related to shift work, such as how to define it? Which shift characteristics or ways to organize working hours are essential to health effects, and how can exposure to these be reliably measured? Second, there are problems in the assessment of the possible effects of selection ("healthy worker effect"): are those starting shift work and especially those staying in it for longer times healthier and/or do they have a higher tolerance for factors affecting health? It would also be important to have information on workers who change the working time model during 
follow-up. Good shift work research faces new challenges resulting from the transition from traditional, lifelong, shift work jobs (mainly related to industrial processes) to flexible, often temporary employment that has grown increasingly during the last decades. In such settings, it is difficult to maintain control over large populations for sufficiently long periods of follow-up to gain accurate exposure data (ie, years of shift work).

Changes in shift systems may thus modify the conclusions on the relevance of different CVD mechanisms. In a systematic review, Driscoll et al (127) found support for the use of forward-rotating shift systems for physiological functions. Changing the backward-rotating shift system to rapidly forward-rotating has been shown to have a favorable effect on blood pressure (128), suggesting that certain features of the shift systems can be critical regarding their health effects. Similarly, increased ergonomic scheduling with a more regular and predictable shift schedule was found to be associated with favorable changes in triglyceride and high-density lipoprotein cholesterol levels (129).

As concluded by Frost et al (3), there is still limited evidence for a causal relationship between shift work and ischemic heart disease. To demonstrate causality, we also need studies on mechanisms. We need more prospective studies with large representative populations, good descriptions of the working hours used, long follow-ups, and reliable measurements of the psychosocial and behavioral stress factors and health outcomes, as well the use of new physiological biomarkers. In an ideal study setting, the participant would be recruited to the study before entering irregular work. This is seldom possible, but research could focus on the "natural intervention" and study the physiological and behavioral effects of entering and leaving irregular work. The role of shift work sleep disturbance in the pathway from shift work to CVD should be investigated. In order to evaluate the role and extent of sleep disturbance, objective measures of sleep in addition to the objective measures of other biomarkers of shift work are needed.

\section{References}

1. Bøggild H, Knutsson A. Shift work, risk factors and cardiovascular disease [review]. Scand J Work Environ Health. 1999;25(2):85-99.

2. Kristensen TS. Cardiovascular diseases and the work environment. A critical review of the epidemiologic literature on nonchemical factors. Scand J Work Environ Health. 1989;15:165-79.

3. Frost P, Kolstad HA, Bonde JP. Shift work and the risk of ischemic heart disease - a systematic review of the epidemiologic evidence. Scand J Work Environ Health. 2009;35(3):163-79.
4. Virkkunen H, Härmä M, Kauppinen T, Tenkanen L. The triad of shift work, occupational noise, and physical workload and risk of coronary heart disease. Occup Environ Med. 2006;63:378-86.

5. Bøggild H. Settling the question - the next review on shift work and heart disease in 2019 [editorial]. Scand J Work Environ Health. 2009;35(3):157-61.

6. Haupt CM, Alte D, Dorr M, Robinson DM, Felix SB, John U, et al. The relation of exposure to shift work with atherosclerosis and myocardial infarction in a general population. Atherosclerosis. 2008;201:205-11.

7. Puttonen S, Kivimäki M, Elovainio M, Pulkki-Råback L, Hintsanen M, Vahtera J, et al. Shift work in young adults and carotid artery intima-media thickness: The Cardiovascular Risk in Young Finns study. Atherosclerosis. 2009;205:608-13.

8. Knauth P. Categories and parameters of shiftwork systems. In: Colquhoun PW, Costa G, Folkard S, Knauth P, editors. Shiftwork: problems and solutions. Frankfurt (Germany): Peter Lang, Europaischer Verlag der Wissenschaften; 1996. p 17-28.

9. World Health Organization (WHO). Prevention of cardiovascular disease: guidelines for assessment and management of total cardiovascular risk. Geneva (Switzerland): WHO press; 2007.

10. Härmä M, Kompier MA, Vahtera J. Work-related stress and health - risks, mechanisms and countermeasures [editorial]. Scand J Work Environ Health. 2006;32(6):413-9.

11. Pollitt RA, Rose KM, Kaufman JS. Evaluating the evidence for models of life course socioeconomic factors and cardiovascular outcomes: a systematic review. BMC Public Health. 2005;5:7.

12. Kivimäki M, Virtanen M, Elovainio M, Kouvonen A, Väänänen A, Vahtera J. Work stress in the etiology of coronary heart disease - a meta-analysis. Scand J Work Environ Health. 2006;32(6):431-42.

13. Bonde JP, Munch-Hansen T, Agerbo E, Suadicani P, Wieclaw J, Westergaard-Nielsen N. Job strain and ischemic heart disease: a prospective study using a new approach for exposure assessment. J Occup Environ Med. 2009;51:732-8.

14. Eller NH, Netterstrøm B, Gyntelberg F, Kristensen TS, Nielsen F, Steptoe A, et al. Work-related psychosocial factors and the development of ischemic heart disease: a systematic review. Cardiol Rev. 2009;17:83-97.

15. Bøggild H, Burr H, Tüchsen F, Jeppesen HJ. Work environment of Danish shift and day workers. Scand J Work Environ Health. 2001;27(2):97-105.

16. Knutsson A, Hallquist J, Reuterwall C, Theorell T, Åkerstedt T. Shiftwork and myocardial infarction: a case-control study. Occup Environ Med. 1999;56:46-50.

17. Peter R, Alfredsson L, Knutsson A, Siegrist J, Westerholm P. Does a stressful psychosocial work environment mediate the effects of shift work on cardiovascular risk factors? Scand J Work Environ Health. 1999;25(4):376-81.

18. Virtanen SV, Notkola V. Socioeconomic inequalities in cardiovascular mortality and the role of work: a register study of Finnish men. Int J Epidemiol. 2002;31:614-21. 
19. Karasek RA, Theorell T. Healthy work: stress, productivity, and the reconstruction of working life. New York (NY): Basic Books; 1990.

20. Parkes KR. Shiftwork, job type, and the work environment as joint predictors of health-related outcomes. J Occup Health Psychol. 1999;4:256-68.

21. Tenkanen L, Sjöblom T, Kalimo R, Alikoski T, Härmä M. Shift work, occupation and coronary heart disease over 6 years of follow-up in the Helsinki Heart Study. Scand J Work Environ Health. 1997;23(4):257-65.

22. Nabe-Nielsen K, Tüchsen F, Christensen KB, Garde AH, Diderichsen F. Differences between day and nonday workers in exposure to physical and psychosocial work factors in the Danish eldercare sector. Scand J Work Environ Health. 2009;35(1):48-55.

23. Ala-Mursula L, Vahtera J, Pentti J, Kivimäki M. Effect of employee worktime control on health: a prospective cohort study. Occup Environ Med. 2004;61:254-61.

24. Ala-Mursula L, Vahtera J, Kivimäki M, Kevin MV, Pentti J. Employee control over working times: associations with subjective health and sickness absences. J Epidemiol Community Health. 2002;56:272-8.

25. Siegrist J, Peter R, Junge A, Cremer P, Seidel D. Low status control, high effort at work and ischemic heart disease: prospective evidence from blue-collar men. Soc Sci Med. 1990;31:1127-34.

26. Pisarski A, Bohle P, Callan VJ. Effects of coping strategies, social support and work-nonwork conflict on shift workers' health. Scand J Work Environ Health. 1998;24 suppl 3:1415 .

27. Albertsen K, Rafnsdóttir G, Grimsmo A, Tómasson K, Kauppinen K. Workhours and worklife balance. SJWEH Suppl. 2008;(5):14-21.

28. Jansen NW, Kant I, Nijhuis FJ, Swaen GM, Kristensen TS. Impact of worktime arrangements on work-home interference among Dutch employees. Scand J Work Environ Health. 2004;30(2):139-48.

29. Costa G, Sartori S, Åkerstedt T. Influence of flexibility and variability of working hours on health and well-being. Chronobiol Int. 2006;23:1125-37.

30. van Amelsvoort LG, Kant IJ, Bultmann U, Swaen GM. Need for recovery after work and the subsequent risk of cardiovascular disease in a working population. Occup Environ Med. 2003;60 suppl 1:i83-7.

31. Kivimäki M, Leino-Arjas P, Kaila-Kangas L, Luukkonen R, Vahtera J, Elovainio M, et al. Is incomplete recovery from work a risk marker of cardiovascular death?: prospective evidence from industrial employees. Psychosom Med. 2006;68:402-7.

32. Jansen N, Kant I, van Amelsvoort L, Nijhuis F, van den Brandt P. Need for recovery from work: evaluating short-term effects of working hours, patterns and schedules. Ergonomics. 2003;46:664-80.

33. van Amelsvoort LG, Jansen NW, Swaen GM, van den Brandt PA, Kant I. Direction of shift rotation among three-shift workers in relation to psychological health and work-family conflict. Scand J Work Environ Health. 2004;30(2):149-56.

34. Mejman TF, Mulder G. Psychological aspects of workload. In: Thierry H, De Wolff CJ, editors. Handbook of work and organizational psychology. 2nd ed. East Sussex (United Kingdom): Psychology Press; 1998.

35. Gallicchio L, Kalesan B. Sleep duration and mortality: a systematic review and meta-analysis. J Sleep Res. 2009;18:148-58.

36. Åkerstedt T, Ingre M, Broman JE, Kecklund G. Disturbed sleep in shift workers, day workers, and insomniacs. Chronobiol Int. 2008;25:333-48.

37. Lusardi P, Zoppi A, Preti P, Pesce RM, Piazza E, Fogari R. Effects of insufficient sleep on blood pressure in hypertensive patients - a 24-h study. Am J Hypertens. 1999;12:63-8.

38. Spiegel K, Leproult R, Van Cauter E. Impact of sleep debt on metabolic and endocrine function. Lancet. 1999;354:1435-9.

39. Spiegel K, Tasali E, Penev P, Van Cauter E. Brief communication: sleep curtailment in healthy young men is associated with decreased leptin levels, elevated ghrelin levels, and increased hunger and appetite. Ann Intern Med. 2004;141:846-50.

40. Meier-Ewert HK, Ridker PM, Rifai N, Regan MM, Price NJ, Dinges DF, et al. Effect of sleep loss on C-reactive protein, an inflammatory marker of cardiovascular risk. J Am Coll Cardiol. 2004;43:678-83.

41. Danesh J, Whincup P, Walker M, Lennon L, Thomson A, Appleby $\mathrm{P}$, et al. Low grade inflammation and coronary heart disease: prospective study and updated meta-analyses. BMJ. 2000;321:199-204.

42. van Leeuwen WM, Lehto $M$, Karisola $P$, Lindholm $H$, Luukkonen R, Sallinen M, et al. Sleep restriction increases the risk of developing cardiovascular diseases by augmenting proinflammatory responses through IL-17 and CRP. Plos One. 2009;4:e4589.

43. Åkerstedt T. Shift work and disturbed sleep/wakefulness. Occup Med (Lond). 2003;53:89-94.

44. Härmä M. Workhours in relation to work stress, recovery and health [review]. Scand J Work Environ Health. 2006;32(6 special issue):502-14.

45. Pilcher JJ, Lambert BJ, Huffcutt AI. Differential effects of permanent and rotating shifts on self-report sleep length: a meta-analytic review. Sleep. 2000;23:155-63.

46. ICSD-2 - International Classification of Sleep Disorders: diagnostic and coding manual. 2 ed. Westchester (IL): American Academy of Sleep Medicine; 2005.

47. Drake CL, Roehrs T, Richardson G, Walsh JK, Roth T. Shift work sleep disorder: prevalence and consequences beyond that of symptomatic day workers. Sleep. 2004;27:1453-62.

48. Radi S, Ostry A, Lamontagne AD. Job stress and other working conditions: relationships with smoking behaviors in a representative sample of working Australians. Am J Ind Med. 2007;50:584-96.

49. Fujino $\mathrm{Y}$, Iso H, Tamakoshi A, Inaba Y, Koizumi A, Kubo $\mathrm{T}$, et al. A prospective cohort study of shift work and risk 
of ischemic heart disease in Japanese male workers. Am J Epidemiol. 2006;164:128-35.

50. Yadegarfar G, McNamee R. Shift work, confounding and death from ischaemic heart disease. Occup Environ Med. 2008;65:158-63.

51. Knutsson A. Methodological aspects of shift-work research. Chronobiol Int. 2004;21:1037-47.

52. van Amelsvoort LG, Jansen NW, Kant I. Smoking among shift workers: more than a confounding factor. Chronobiol Int. 2006;23:1105-13.

53. Nabe-Nielsen K, Garde AH, Tüchsen F, Hogh A, Diderichsen F. Cardiovascular risk factors and primary selection into shift work. Scand J Work Environ Health. 2008;34(3):206-12.

54. Lennernäs M, Hambraeus L, Åkerstedt T. Shift related dietary intake in day and shift workers. Appetite. 1995;25:253-65.

55. Morikawa Y, Miura K, Sasaki S, Yoshita K, Yoneyama S, Sakurai M, et al. Evaluation of the effects of shift work on nutrient intake: a cross-sectional study. J Occup Health. 2008;50:270-8.

56. Morikawa Y, Nakagawa H, Miura K, Soyama Y, Ishizaki M, Kido T, et al. Effect of shift work on body mass index and metabolic parameters. Scand J Work Environ Health. 2007;33(1):45-50.

57. Dochi M, Suwazono Y, Sakata K, Okubo Y, Oishi M, Tanaka K, et al. Shift work is a risk factor for increased total cholesterol level: a 14-year prospective cohort study in 6886 male workers. Occup Environ Med. 2009;66:592-7.

58. Biggi N, Consonni D, Galluzzo V, Sogliani M, Costa G. Metabolic syndrome in permanent night workers. Chronobiol Int. 2008;25:443-54.

59. Ghiasvand M, Heshmat R, Golpira R, Haghpanah V, Soleimani A, Shoushtarizadeh P, et al. Shift working and risk of lipid disorders: a cross-sectional study. Lipids Health Dis. 2006;5:9.

60. Sookoian S, Gemma C, Fernandez Gianotti T, Burgueno A, Alvarez A, et al. Effects of rotating shift work on biomarkers of metabolic syndrome and inflammation. J Intern Med. 2007;261:285-92.

61. Cappuccio FP, Taggart FM, Kandala NB, Currie A, Peile E, Stranges S, et al. Meta-analysis of short sleep duration and obesity in children and adults. Sleep. 2008;31:619-26.

62. Marshall NS, Glozier N, Grunstein RR. Is sleep duration related to obesity?: a critical review of the epidemiological evidence. Sleep Med Rev. 2008;12:289-98.

63. Suwazono Y, Dochi M, Sakata K, Okubo Y, Oishi M, Tanaka $\mathrm{K}$, et al. A longitudinal study on the effect of shift work on weight gain in male Japanese workers. Obesity (Silver Spring). 2008;16:1887-93.

64. Hansson GK. Inflammation, atherosclerosis, and coronary artery disease. N Engl J Med. 2005;352:1685-95.

65. Nishitani N, Sakakibara H. Subjective poor sleep and white blood cell count in male Japanese workers. Ind Health. 2007;45:296-300.

66. Curti R, Radice L, Cesana GC, Zanettini R, Grieco A. Work stress and immune system: lymphocyte reactions during rotating shift work: preliminary results. Med Lav. 1982;73:564-9.

67. Nakano Y, Miura T, Hara I, Aono H, Miyano N, Miyajima K, et al. The effect of shift work on cellular immune function. J Hum Ergol (Tokyo). 1982;11 suppl:131-7.

68. Kobayashi F, Furui H, Akamatsu Y, Watanabe T, Horibe H. Changes in psychophysiological functions during night shift in nurses: influence of changing from a full-day to a half-day work shift before night duty. Int Arch Occup Environ Health. 1997;69:83-90.

69. Okamoto H, Tsunoda T, Teruya K, Takeda N, Uemura T, Matsui T, et al. An occupational health study of emergency physicians in Japan: health assessment by immune variables (CD4, CD8, CD56, and NK cell activity) at the beginning of work. J Occup Health. 2008;50:136-46.

70. Antoniades C, Antonopoulos AS, Tousoulis D, Marinou K, Stefanadis C. Homocysteine and coronary atherosclerosis: from folate fortification to the recent clinical trials. Eur Heart J. 2009;30:6-15.

71. McCully KS. Chemical pathology of homocysteine, IV: excitotoxicity, oxidative stress, endothelial dysfunction, and inflammation. Ann Clin Lab Sci. 2009;39:219-32.

72. Copertaro A, Bracci M, Barbaresi M, Santarelli L. Assessment of cardiovascular risk in shift healthcare workers. Eur J Cardiovasc Prev Rehabil. 2008;15:224-9.

73. Martins PJ, D'Almeida V, Vergani N, Perez AB, Tufik S. Increased plasma homocysteine levels in shift working bus drivers. Occup Environ Med. 2003;60:662-6.

74. Lavie L, Lavie P. Elevated plasma homocysteine in older shiftworkers: a potential risk factor for cardiovascular morbidity. Chronobiol Int. 2007;24:115-28.

75. Mahmoodi BK, Gansevoort RT, Veeger NJ, Matthews AG, Navis G, Hillege HL, et al. Microalbuminuria and risk of venous thromboembolism. JAMA. 2009;301:1790-7.

76. Weir MR. Microalbuminuria and cardiovascular disease. Clin J Am Soc Nephrol. 2007;2:581-90.

77. Boogaard PJ, Caubo ME. Increased albumin excretion in industrial workers due to shift work rather than to prolonged exposure to low concentrations of chlorinated hydrocarbons. Occup Environ Med. 1994;51:638-41.

78. Karlsson BH, Knutsson AK, Lindahl BO, Alfredsson LS. Metabolic disturbances in male workers with rotating threeshift work: results of the WOLF study. Int Arch Occup Environ Health. 2003;76:424-30.

79. Peternel P, Stegnar M, Salobir U, Salobir B, Keber D, Vene N. Shift work and circadian rhythm of blood fibrinolytic parameters. Fibrinolysis. 1990;4 suppl 2:113-5.

80. Chung MH, Kuo TB, Hsu N, Chu H, Chou KR, Yang CC. Sleep and autonomic nervous system changes - enhanced cardiac sympathetic modulations during sleep in permanent night shift nurses. Scand J Work Environ Health. 2009;35(3):180-7.

81. Furlan R, Barbic F, Piazza S, Tinelli M, Seghizzi P, Malliani A. Modifications of ardiac autonomic profile associated with a shift schedule of work. Circulation. 2000;102:1912-6. 
82. Ito H, Nozaki M, Maruyama T, Kaji Y, Tsuda Y. Shift work modifies the circadian patterns of heart rate variability in nurses. Int J Cardiol. 2001;79:231-6.

83. Munakata M, Ichi S, Nunokawa T, Saito Y, Ito N, Fukudo $\mathrm{S}$, et al. Influence of night shift work on psychologic state and cardiovascular and neuroendocrine responses in healthy nurses. Hypertens Res. 2001;24:25-31.

84. van Amelsvoort LG, Schouten EG, Maan AC, Swenne CA, Kok FJ. Occupational determinants of heart rate variability. Int Arch Occup Environ Health. 2000;73:255-62.

85. Murata K, Yano E, Hashimoto H, Karita K, Dakeishi M. Effects of shift work on QTc interval and blood pressure in relation to heart rate variability. Int Arch Occup Environ Health. 2005;78:287-92.

86. van Amelsvoort LG, Schouten EG, Maan AC, Swenne CA, Kok FJ. Changes in frequency of premature complexes and heart rate variability related to shift work. Occup Environ Med. $2001 ; 58: 678-81$.

87. Adameova A, Abdellatif Y, Dhalla NS. Role of the excessive amounts of circulating catecholamines and glucocorticoids in stress-induced heart disease. Can J Physiol Pharmacol. 2009;87:493-514.

88. Hennig J, Kieferdorf P, Moritz C, Huwe S, Netter P. Changes in cortisol secretion during shiftwork: implications for tolerance to shiftwork? Ergonomics. 1998;41:610-21.

89. Malmberg B, Persson R, Jönsson BA, Erfurth EM, Flisberg $\mathrm{P}$, Ranklev E, et al. Physiological restitution after night-call duty in anaesthesiologists: impact on metabolic factors. Acta Anaesthesiol Scand. 2007;51:823-30.

90. Roden M, Koller M, Pirich K, Vierhapper H, Waldhauser F. The circadian melatonin and cortisol secretion pattern in permanent night shift workers. Am J Physiol. 1993;265:2617.

91. Touitou Y, Motohashi Y, Reinberg A, Touitou C, Bourdeleau P, Bogdan A, et al. Effect of shift work on the night-time secretory patterns of melatonin, prolactin, cortisol and testosterone. Eur J Appl Physiol Occup Physiol. 1990;60:288-92.

92. Boucsein W, Ottmann W. Psychophysiological stress effects from the combination of night-shift work and noise. Biol Psychol. 1996;42:301-22.

93. Theorell T, Åkerstedt T. Day and night work: changes in cholesterol, uric acid, glucose and potassium in serum and in circadian patterns of urinary catecholamine excretion: a longitudinal cross-over study of railway workers. Acta Med Scand.1976;200:47-53.

94. Amir O, Alroy S, Schliamser JE, Asmir I, Shiran A, Flugelman MY, et al. Brachial artery endothelial function in residents and fellows working night shifts. Am J Cardiol. 2004;93:947-9.

95. Kroenke CH, Spiegelman D, Manson J, Schernhammer ES, Colditz GA, Kawachi I. Work characteristics and incidence of type 2 diabetes in women. Am J Epidemiol. 2007;165:17583.

96. Kawachi I, Colditz GA, Stampfer MJ, Willett WC, Manson JE, Speizer FE, et al. Prospective study of shift work and risk of coronary heart disease in women. Circulation. 1995;92:3178-82.
97. Karlsson B, Alfredsson L, Knutsson A, Andersson E, Torén K. Total mortality and cause-specific mortality of Swedish shiftand dayworkers in the pulp and paper industry in 1952-2001. Scand J Work Environ Health. 2005;31(1):30-5.

98. Kawakami N, Araki S, Takatsuka N, Shimizu H, Ishibashi H. Overtime, psychosocial working conditions, and occurrence of non-insulin dependent diabetes mellitus in Japanese men. J Epidemiol Community Health. 1999;53:359-63.

99. Morikawa Y, Nakagawa H, Miura K, Soyama Y, Ishizaki M, Kido T, et al. Shift work and the risk of diabetes mellitus among Japanese male factory workers. Scand J Work Environ Health. 2005;31:179-83

100. Suwazono Y, Sakata K, Okubo Y, Harada H, Oishi M, Kobayashi E, et al. Long-Term Longitudinal Study on the Relationship Between Alternating Shift Work and the Onset of Diabetes Mellitus in Male Japanese Workers. J Occup Environ Med. 2006;48:455-61.

101. Galassi A, Reynolds K, He J. Metabolic syndrome and risk of cardiovascular disease: a meta-analysis. Am J Med. 2006;119:812-9.

102. Ha M, Park J. Shiftwork and metabolic risk factors of cardiovascular disease. J Occup Health. 2005;47:89-95.

103. Nagaya T, Yoshida H, Takahashi H, Kawai M. Markers of insulin resistance in day and shift workers aged 30-59 years. Int Arch Occup Environ Health. 2002;75:562-8.

104. Esquirol Y, Bongard V, Mabile L, Jonnier B, Soulat JM, Perret B. Shift work and metabolic syndrome: respective impacts of job strain, physical activity, and dietary rhythms. Chronobiol Int. 2009;26:544-59.

105. De Bacquer D, Van Risseghem M, Clays E, Kittel F, De Backer G, Braeckman L. Rotating shift work and the metabolic syndrome: a prospective study. Int J Epidemiol. 2009;38:848-54.

106. Lin YC, Hsiao TJ, Chen PC. Persistent rotating shift-work exposure accelerates development of metabolic syndrome among middle-aged female employees: a five-year follow-up. Chronobiol Int. 2009;26:740-55.

107. Pietroiusti A, Neri A, Somma G, Coppeta L, Iavicoli I, Bergamaschi $\mathrm{A}$, et al. Incidence of metabolic syndrome among night shift health care workers. Occup Environ Med. 2010;67(1):54-7.

108. Murata K, Yano E, Shinozaki T. Cardiovascular dysfunction due to shift work. J Occup Environ Med. 1999;41:748-53.

109. Di Lorenzo L, De Pergola G, Zocchetti C, L'Abbate N, Basso A, Pannacciulli N, et al. Effect of shift work on body mass index: results of a study performed in 319 glucose-tolerant men working in a Southern Italian industry. Int J Obes Relat Metab Disord. 2003;27:1353-8.

110. Ohira T, Tanigawa T, Iso H, Odagiri Y, Takamiya T, Shimomitsu T, et al. Effects of shift work on 24-hour ambulatory blood pressure and its variability among Japanese workers. Scand J Work Environ Health. 2000;26(5):421-6.

111. Suwazono Y, Dochi M, Sakata K, Okubo Y, Oishi M, Tanaka $\mathrm{K}$, et al. Shift work is a risk factor for increased blood pressure in Japanese men: a 14-year historical cohort study. Hypertension. 2008;52:581-6. 
112. Murata K, Yano E, Shinozaki T. Impact of shift work on cardiovascular functions in a 10-year follow-up study. Scand J Work Environ Health. 1999;25(3):272-7.

113. Virkkunen H, Härmä M, Kauppinen T, Tenkanen L. Shift work, occupational noise and physical workload with ensuing development of blood pressure and their joint effect on the risk of coronary heart disease. Scand J Work Environ Health. 2007;33(6):425-34.

114. Nazri SM, Tengku MA, Winn T. The association of shift work and hypertension among male factory workers in Kota Bharu, Kelantan, Malaysia. Southeast Asian J Trop Med Public Health. 2008;39:176-83.

115. Morikawa Y, Nakagawa H, Miura K, Ishizaki M, Tabata M, Nishijo M, et al. Relationship between shift work and onset of hypertension in a cohort of manual workers. Scand J Work Environ Health. 1999;25(2):100-4.

116. Sakata K, Suwazono Y, Harada H, Okubo Y, Kobayashi E, Nogawa K. The relationship between shift work and the onset of hypertension in male Japanese workers. J Occup Environ Med. 2003;45:1002-6.

117. Oishi M, Suwazono Y, Sakata K, Okubo Y, Harada H, Kobayashi E, et al. A longitudinal study on the relationship between shift work and the progression of hypertension in male Japanese workers. J Hypertens. 2005;23:2173-8.

118. Yamasaki F, Schwartz JE, Gerber LM, Warren K, Pickering TG. Impact of shift work and race/ethnicity on the diurnal rhythm of blood pressure and catecholamines. Hypertension. 1998;32:417-23.

119. Fialho G, Cavichio L, Povoa R, Pimenta J. Effects of 24-h shift work in the emergency room on ambulatory blood pressure monitoring values of medical residents. Am J Hypertens. 2006;19:1005-9.

120. Lo SH, Liau CS, Hwang JS, Wang JD. Dynamic blood pressure changes and recovery under different work shifts in young women. Am J Hypertens. 2008;21:759-64.
121. Goto T, Yokoyama K, Araki T, Miura T, Saitoh H, Saitoh M, et al. Identical blood pressure levels and slower heart rates among nurses during night work and day work. J Hum Hypertens. 1994;8:11-4.

122. Kitamura T, Onishi K, Dohi K, Okinaka T, Ito M, Isaka N, et al. Circadian rhythm of blood pressure is transformed from a dipper to a non-dipper pattern in shift workers with hypertension. J Hum Hypertens. 2002;16:193-7.

123. Ayas NT, White DP, Manson JE, Stampfer MJ, Speizer FE, Malhotra A, et al. A prospective study of sleep duration and coronary heart disease in women. Arch Intern Med. 2003;163:205-9.

124. Eaker ED, Pinsky J, Castelli WP. Myocardial-Infarction and coronary death among women - psychosocial predictors from a 20-year follow-up of women in the Framingham-Study. Am J Epidemiol. 1992;135:854-64.

125. Ursin R, Baste V, Moen BE. Sleep duration and sleep-related problems in different occupations in the Hordaland Health Study. Scand J Work Environ Health. 2009;35(3):193-202.

126. Hublin C, Partinen M, Koskenvuo M, Kaprio J. Sleep and mortality: a population based 22-year follow-up study. Sleep. 2007;30:1245-53.

127. Driscoll TR, Grunstein RR, Rogers NL. A systematic review of the neurobehavioural and physiological effects of shiftwork systems. Sleep Med Rev. 2007;11:179-94.

128. Viitasalo K, Kuosma E, Laitinen J, Härmä M. Effects of shift rotation and the flexibility of a shift system on daytime alertness and cardiovascular risk factors. Scand J Work Environ Health. 2008;34(3):198-205.

129. Bøggild H, Jeppesen HJ. Intervention in shift scheduling and changes in biomarkers of heart disease in hospital wards. Scand J Work Environ Health. 2001;27(2):87-96.

Received for publication: 5 November 2009 